\title{
Felsic magma diversity, \& triumphs and perils of granite typology
}

\author{
C.F. MilleR', J.S. MILLER', G.A.R. GuALDA'
}

'Vanderbilt University, Earth \& Environmental Sciences, Nashville TN USA, calvin.miller@vanderbilt.edu 2SJSU, Geology, San Jose USA, jonathan.miller@SJSU.edu

Tuttle \& Bowen (1958; T\&B) demonstrated coincidence of minimum melt with dominant compositions of both silicic volcanic ( $\sim$ rhyolite) and plutonic ( $\sim$ granite) rocks. This implied a common origin for magmatic rhyolites and controversial granites, partly solving the "granite problem." But were all granites and all rhyolites formed in the same way? Or were distinct processes and sources involved, masked by convergence toward qtz-feldsp-melt equilibrium? Are felsic magmas generated by crustal anatexis, by fractional crystallization of mantle magma, or both?

Chappell \& White (1974; C\&W), using a combination of classical and new techniques, demonstrated that Lachlan Fold Belt granites were generated from distinguishable sources. Petrographic and geochemical characteristics indicated contributions from both metasedimentary (S-type) and igneous (I-type) sources. Thus was born granite "typology," and an appreciation for recognizable diversity in felsic magmas (at least those from which granites form).

Initially inspired by $\mathrm{C} \& \mathrm{~W}$, an ever-expanding host of studies has demonstrated diversity of felsic magmas/rocks in terms of source materials; involvement of juvenile magma; tectonic setting; volume and time scales; extraction, ascent, storage, emplacement $+/$ - eruption; $\mathrm{T} / \mathrm{H}_{2} \mathrm{O}$; and fluctuating conditions. In response to this diversity, granite typologies - elemental discrimination, tectonic, associationbased, as well as expanded alphabetic - have blossomed.

We view typology today as reflecting both progress toward and obstacles to understanding of felsic magmatism: Progress: appreciation for magmatic diversity; correlation of significant characteristics; potential for insights into tectonic and petrogenetic processes. Obstacles: (1) Misplaced faith in typology as interpretation; (2) Simplistic application of often abbreviated criteria; (3) Failure to specify criteria for "types;" (4) Confusing array of partially overlapping typologies; (5) Absence of or minimal attention to volcanism (cf. significance in $T \& B$ )

Felsic magmatists should (1) Be aware of insights from typology, but specify criteria and DON'T prioritize simply "typing" in lieu of critical interpretation; (2) Apply lessons from volcanics to granites (and vice versa); (3) Recognize that "types" are pigeonholes within continua and that felsic magmas have multiple components and diverse histories. 
This abstract is too long to be accepted for publication.

Please revise it so that it fits into the column on one page. 